\title{
Toezicht en governance in de open samenleving*
}

\author{
Judith van Erp
}

\section{Inleiding}

In de moderne samenleving worden vrijwel alle basisvoorzieningen - voedsel, gezondheidszorg, financiën, vervoer, energie, huisvesting, informatie en communicatie - aangeboden via gereguleerde markten. ${ }^{1}$ Vaak zijn deze markten internationaal, met multinationale ondernemingen als belangrijkste spelers. Multinationale ondernemingen zijn niet meer alleen maar belangrijk in commerciële markten, maar ze hebben ook hun intrede gedaan in het aanbod van publieke diensten. In de gezondheidszorg, verzekeringsmarkt, en volkshuisvesting zijn private equity investeerders inmiddels geen uitzondering meer naast semipublieke organisaties. Wat is de betekenis van deze ontwikkelingen voor de bestuurskunde? En hoe speelt mijn onderzoek hierop in? In deze bijdrage schets ik kort de betekenis van de regulerende staat en betoog ik dat vraagstukken rondom toezicht en handhaving meer aandacht verdienen van bestuurskundigen. Ik laat zien dat een interdisciplinaire aanpak, zoals die in het vakgebied 'Regulatory Governance', cruciaal is voor beantwoording van deze vragen, en illustreer dit aan de hand van de meerwaarde van een criminologisch perspectief op relaties tussen markt en staat. Tot slot ga ik kort in op mijn eigen onderzoeksagenda.

\section{De regulerende staat}

Regulering van markten is in deze tijd een van de belangrijkste besturingsvormen van de samenleving, en daarmee tevens een belangrijk onderwerp voor bestuurskundig onderzoek. In mijn leerstoel 'Publieke Instituties' richt ik me op dat deel van het openbaar bestuur dat wordt gekarakteriseerd als de 'regulatory state' (Majone, 1994): de instituties voor inrichting en controle van markten als platform voor maatschappelijke ordening, in tegenstelling tot ordening door herverdeling of publieke dienstverlening zoals in de verzorgingsstaat (Fenger, 2016), of door repressieve controle zoals in de veiligheidsstaat (Boutellier, 2005: Schuilenburg, 2012).

De reguleringsstaat heeft sinds de jaren negentig een ontwikkeling doorgemaakt die Levi-Faur (2013) beeldend beschrijft als een odyssee: een epische opmars van regulering als primair sturingsmiddel van de staat, door (deels) onafhankelijke toezichtsorganen met regulerende bevoegdheden die relatief onafhankelijk van de

* Prof. dr. J.G. van Erp bekleedt de leerstoel 'Publieke Instituties' aan de Universiteit Utrecht, binnen het departement Bestuurs- en Organisatiewetenschap, en is verbonden aan het strategische thema “Instituties voor Open Samenlevingen' van de Universiteit Utrecht.

1 In Nederland zijn onderwijs en veiligheidszorg vooralsnog grotendeels van marktwerking uitgezonderd. 
politiek markten aansturen door middel van flexibele regulering. Het marktwerkingsmodel is gestaag opgetrokken van het economische naar het sociale domein en heeft zich vanuit westerse neoliberale economieën mondiaal verspreid (Jordana, Fernández-i-Marín, X., \& Bianculli., 2018; Levi-Faur, 2012), niet alleen als empirisch fenomeen, maar ook als normatief ideaal (Ruggie, 2018; Roberts, 2010. Deze ontwikkeling loopt parallel aan de globalisering van productie, dienstverlening, informatievoorziening, en kapitaalverstrekking, en de multinational als hét standaardmodel voor economische activiteiten in transnationaal verband (Ruggie, 2018). De regulerende staat stuurt de maatschappij niet via herverdeling, zoals de verzorgingsstaat, of samenwerking, zoals 'collaborative governance', maar via regels: regelgeving, marktordening, verantwoording, toezicht, en handhaving zijn de centrale sturingsmechanismen in mondiale markten (Levi-Faur, 2012).

De regulerende staat heeft ook geleid tot een enorme groei aan publieke toezichthouders die naleving bevorderen en risico's beheersen (Jordana et al., 2018). Maar in het governance tijdperk opereren deze publieke toezichthouders niet alleen hiërarchisch, maar ook zij aan zij met ondernemingen, brancheorganisaties, private toezichthouders, maatschappelijke controleurs, belangenorganisaties, media en intermediairs, bij het controleren van een explosie aan publieke en private regels, normen, standaarden, codes en contracten - al met al een lappendeken van actoren en arrangementen of, naar analogie van Presdee, een bonte carnavalsstoet van controleurs en handhavers (Schuilenburg 2012, pp. 7,71 ). De macht is bovendien verschoven van formele instituties, naar informele en ambigue mechanismen zoals internet en sociale media, waarvan een controlerende werking uitgaat. De regulerende staat is daarmee onderdeel van een veel bredere regulerende beweging.

\section{Legitimiteit en gezag van toezicht in netwerken}

Publiek toezicht, uitgeoefend door inspecties en markttoezichthouders, omgevingsdiensten en Europese toezichthouders, wordt vaak beschouwd als het apolitieke sluitstuk van de beleidscyclus en is, wellicht om die reden, minder geproblematiseerd in bestuurskundige analyses (Coen \& Pegram, 2018). Ook in de praktijk van het openbaar bestuur krijgt toezicht disproportioneel weinig aandacht en wordt het vaak als een last gezien - tot er een incident gebeurt. Deze onderwaardering komt voort uit een tekortschietend begrip van de reguleringsstaat als hét sturingsmodel van de 21ste eeuw. In de reguleringsstaat is handhaving geen uitvloeisel van beleid, maar zijn regulering, toezicht en handhaving de centrale en primaire vormen van sturing en machtsuitoefening (Levi-Faur, 2012). In mijn onderzoek naar publieke instituties staat dit toezicht dan ook centraal, niet als uitvoering van beleid maar als zelfstandige publieke institutie te midden van private toezichtinstituties. In dit dynamische veld krijgen allerlei klassiek bestuurskundige vragen over legitimiteit en gezag van bestuur in publiek-private constellaties een nieuwe invulling.

Allereerst betekent de zelfstandige en onafhankelijke positie van toezichthouders in de regulerende staat dat zij 'politieke' beslissingen nemen, zonder sterke demo- 
cratische legitimatie en controle zoals dat bij reguliere uitvoeringsorganisaties het geval is. Wetgeving bevat vaker open normen en principes, die toezichthouders in de praktijk flexibel moeten invullen. In situaties waarin nationale wetgeving geen antwoord biedt, moeten zij daadkrachtig optreden tegen risico's - soms onder hoge tijdsdruk, op basis van onvolledige kennis, of tegen zeer machtige ondernemingen. De WRR formuleert als kerntaak voor toezichthouders: het waarborgen van de publieke belangen - waarbij toezichthouders zelfstandige afwegingen moeten maken tussen belangen (WRR, 2013). Juist in een tijd waarin politieke en maatschappelijke tegenstellingen over publieke vraagstukken sterker worden (denk aan klimaat, gaswinning, vrijheid van onderwijs, vaccinaties), worden toezichthouders 'politieker'. Maar deze wendbare en politiek gevoelige rol staat op gespannen voet met de rechtmatigheid, zorgvuldigheid en apolitieke expertrol die van toezichthouders wordt verwacht. Tegelijkertijd wordt in een tijdperk van horizontalisering hiërarchisch gezag minder geaccepteerd. Dat levert vragen op over de legitimiteit, politieke onafhankelijkheid en effectiviteit van toezicht in moderne, vloeibare verhoudingen (Van Erp \& Van der Steen, 2018).

In de tweede plaats ontstaat door globalisering, technologische vooruitgang en toenemende verbondenheid in netwerken met 'vloeibare' verhoudingen een omgeving die vaak als vluchtig, onzeker, complex en ambigu wordt gekarakteriseerd (Van der Wal, 2017). Dat biedt ondernemingen mogelijkheden voor innovatie en groei, maar ook gelegenheden om het grijze gebied op te zoeken of gedrag te vertonen dat weliswaar legaal, maar toch schadelijk is - denk aan de manipulatie van emissies van Volkswagens op de testbank, datamacht van Facebook, of belastingontwijking. Door deze openheid in economische verhoudingen staat de open samenleving in politieke zin onder druk (Claassen \& Van Erp, 2019). Ook ontstaan lacunes en risico's door falend toezicht in het buitenland en doordat steeds vaker producten en diensten worden aangeboden die zich bewust aan (nationaal) toezicht onttrekken, zoals online kansspelen, virtuele financiële producten, belastingconstructies, of geneesmiddelenverkoop via internet. Hier klinkt vaak de roep om krachtig toezicht, en de vraag dringt zich op welke reacties toezichthouders kunnen geven zonder wettelijke mogelijkheden om in te grijpen.

Ten derde opereren toezichthouders zoals gezegd in netwerken van private, internationale en maatschappelijke controleurs. Horizontale en verticale verhoudingen vermengen zich. Horizontaal verbinden en samenwerken is noodzakelijk om effectief te zijn. Tegelijkertijd vraagt de maatschappij om gezaghebbend optreden, streng straffen, een grote zichtbaarheid en openbaarheid van toezicht, inclusief naming and shaming. De spanningen tussen straffen en samenwerking, autoriteit en verbinding, nationaal gezag en internationale afstemming, transparantie, verantwoording en vertrouwen, maken dat bestuurlijke dilemma's in de relatie tussen overheid en samenleving juist in de handhaving op scherp staan. Dit geldt zowel op het niveau van de toezichtsautoriteiten als van de individuele inspecteurs die op 'street level' niveau regels moeten toepassen, en soms worstelen met hun dubbelrol als 'adviseur' en 'politieagent' (Van Wingerde, Mascini, Barth., 2018). 


\section{Een grenzen-loze wereld vraagt om onderzoek over de grenzen van disciplines}

Bestuurskunde is, als interdisciplinaire wetenschap met aandacht voor de verbinding tussen publiek en privaat, netwerken en governance, goed gepositioneerd om deze vragen te beantwoorden. Diverse collega-bestuurskundigen houden zich daarom met toezichtsgerelateerde vraagstukken bezig, zowel binnen mijn thuisdepartement USBO als bij andere universiteiten. Tegelijkertijd is duidelijk dat deze vragen het openbaar bestuur overstijgen. Binnen de Universiteit Utrecht richtten we daarom het interdisciplinaire platform op voor onderzoek naar Markten en Ondernemingen in de Open Samenleving (Claassen \& Van Erp, 2019). Om toezichtsvragen ook breder in interdisciplinaire onderzoeksnetwerken te agenderen stelden Martijn van der Steen en ik, in samenwerking met inspecties en markttoezichthouders, vorig jaar een Wetenschapsagenda Toezicht op, die inmiddels door de Inspectieraad is voorgedragen voor programmering als onderdeel van de Nationale Wetenschapsagenda (Van Erp \& Van der Steen, 2018).

Internationaal vindt onderzoek naar de regulerende staat voornamelijk plaats in het interdisciplinaire vakgebied 'Regulatory Governance', waarin mijn onderzoek is gepositioneerd. Regulatory Governance is inmiddels stevig gevestigd als institutioneel veld (Lodge, 2016; Levi-Faur, 2013, en omvat bestuurskunde, recht, rechtssociologie, politieke econonomie, internationale betrekkingen en criminologie. Werken op het snijvlak van disciplines loopt als een rode draad door mijn carrière, waarin ik bestuurlijke vragen rondom toezicht, rechtshandhaving en regelnaleving heb beantwoord vanuit de rechtssociologie (als postdoc aan de EUR), de criminologie (als postdoc, universitair docent en hoofddocent) en de bestuurskunde (als promovenda en hoogleraar). Op dit snijvlak kunnen vragen over de wisselwerking tussen sturing en naleving, en over de relatie tussen formele en informele beïnvloeding van schadelijk gedrag van organisaties, het best worden beantwoord. Maar waar deze disciplines een gedeeld verleden hebben en elkaar ontmoeten in de empirische werkelijkheid, zijn ze als wetenschappelijke disciplines uit elkaar gegroeid. Bestuurskunde, Regulatory Governance en criminologie zijn inmiddels grotendeels gescheiden circuits, met eigen tijdschriften, congressen en literatuur. In mijn ogen is dat een verarming. Hieronder licht ik kort toe hoe mijn verblijf in de criminologie mijn blik heeft verrijkt. ${ }^{2}$

\section{Criminologie en 'governance'}

'Regulatory Governance' is in de jaren negentig ontstaan vanuit onder andere de criminologie - een van de belangrijkste hedendaagse criminologen, John Braithwaite, was een van de oprichters van het tijdschrift Regulation and Governance (Braithwaite, Coglianese, Levi-Faur, 2007). Organisatiecriminologie richt de blik op de mogelijkheden die de organisatie - als structuur, cultuur en als rechtsvorm

2 Dit deel is gebaseerd op Almond \& Van Erp, 'Regulation and governance versus criminology: Disciplinary divides, intersections, and opportunities', Regulation \& Governance (2019). Wij uiten in dat artikel overigens ook kritiekpunten op onderzoek naar organisatiecriminaliteit, waarvoor ik kortheidshalve verwijs naar het artikel. 
- en de organisatie-omgeving bieden voor schadelijk gedrag. ${ }^{3}$ Een (organisatie)criminologisch perspectief richt in de eerste plaats de aandacht op de symbiotische relaties tussen politieke en economische elites die organisatiecriminaliteit faciliteren. Organisatiecriminaliteit is crime of the powerful en onderzoek in deze traditie richt zich op de wijze waarop regulering en toezicht - of het ontbreken ervan (Pearce, 1976; Barak, 2015) - een uitdrukking vormen van economische machtsverhoudingen. Zo wordt organisatiecriminaliteit verklaard vanuit regimes of permission of benign neglect van markten door toezichthouders (Whyte, 2014), die ertoe leiden dat ondernemingen met rust worden gelaten of met fluwelen handschoenen worden aangepakt.

In de loop van de jaren is 'criminaliteit' in Regulatory Governance wat op de achtergrond geraakt ten gunste van een neutraler 'risico'-perspectief. Regulatory Governance bevraagt vaker de effectiviteit van reguleringsarrangementen bij het beheersen van risico's dan hun onderliggende en resulterende machtsaspecten - politieke vraagstukken worden daarmee soms gereduceerd tot instrumentele problemen (Mascini, 2013). De enorme instrumentele, structurele en discursieve macht van multinationale ondernemingen in mondiale markten vraagt echter om een fundamentelere problematisering van de relatie tussen overheden en ondernemingen. De multinationale onderneming is een opzichzelfstaande, mondiale institutie, in politieke macht, gezag en autonomie vergelijkbaar met staten. Ook in governance-literatuur pleit men dan ook voor 'much more attention to the political strategic environment that informs diverse regulatory goals' (Coen \& Pegram, 2018, p. 418). In de bestuurskunde en politicologie is veel aandacht voor lobbygedrag van ondernemingen bij de totstandkoming van wetgeving, maar onderzoek naar de macht van ondernemingen in de fase van handhaving, bijvoorbeeld bij het onderhandelen over strafrechtelijke schikkingen, treffen we vooral in juridische en criminologische literatuur. Het bestuurskundig begrip van de positie van de ondernemingen dreigt daarmee incompleet te raken. Een tweede punt dat vanuit criminologisch perspectief opvalt aan governance-benaderingen, is dat ze een tamelijk welwillende houding innemen ten opzichte van private regulering, zelfregulering en publiek-private samenwerking. Governance-benaderingen gaan uit van de onvermijdelijkheid van samenwerking tussen publieke en private actoren. Maar de normatieve omarming van het principe, wordt soms ook uitgestrekt naar de samenwerking in de praktijk, waardoor deze samenwerking niet altijd voldoende geproblematiseerd of kritisch benaderd wordt. Onderzoek naar bijvoorbeeld de Libor-affaire (Jordanoska \& Lord, 2019), de Volkswagen-dieselfraude (Van Rooij \& Fine, 2018) en de Deepwater Horizon-olieramp (Mills \& Koliba, 2015) laten zien dat zelfregulering vaak niet krachtig genoeg is.

Bovendien is gezien het open en flexibele karakter van regulering een belangrijke rol voor ondernemingen weggelegd in de interpretatie van principes. De beteke-

3 Organisatiecriminaliteit wordt gedefinieerd als het illegaal en schadelijk gedrag van legitieme organisaties (of hun medewerkers) ten gunste van deze organisaties, in tegenstelling tot wat vaak witteboordencriminaliteit wordt genoemd (individuele misdrijven voor primair eigen gewin en vaak ten koste van de organisatie). Belastingfraude, privacyschendingen, milieucriminaliteit door ondernemingen, en kartels, zijn voorbeelden van organisatiecriminaliteit. 
nis van en invulling aan 'naleving' gebeurt in samenspraak met ondernemingen, in experimentele reguleringsvormen zoals een 'regulatory sandbox' voor regulering van fintech. Dit soort 'samenwerkingstoezicht' kan de verantwoordelijkheid van ondernemingen versterken. Maar zonder voldoende tegenwicht kunnen ondernemingen regels ook eenzijdig op voor hen gunstige wijze interpreteren, zeker als er in de politiek minder overeenstemming bestaat over maatschappelijke doelstellingen.

De samenwerking tussen ondernemingen en publieke toezichthouders in de uitvoering van het toezicht wordt door governance wetenschappers misschien te weinig geproblematiseerd. Horizontaal toezicht, zelfregulering en systeemtoezicht kunnen het schadelijke karakter van organisatiecriminaliteit verhullen (Meerts, 2018) en bijdragen aan morele ambiguïteit, en daarmee ook tolerante regulering in de hand werken (Nelken, 2012). Waar governance in theorie betekent dat meerdere actoren op meerdere niveaus reguleren, betekent het in de praktijk vaak dat de overheid een stapje terug doet. In mijn oratie heb ik daarom de vraag gesteld of governance inderdaad betekent dat de macht van de staat gespreid wordt en diversifieert, zoals de optimistische verwachting luidt, of dat gedeelde macht uiteindelijk betekent dat niemand verantwoordelijk is - met andere woorden of toezicht echt anders wordt en niet gewoon minder (Van Erp, 2016, p. 33).

\section{Agenda}

In mijn oratie (Van Erp, 2016) kondigde ik een onderzoeksagenda aan naar nieuwe toezichtsarrangementen voor de open samenleving, waarin publieke toezichthouders beter gebruikmaken van spontane, maatschappelijke controle, zoals klokkenluiders, NGO's, internet, media, en burgers. Op dit moment gaat het belangrijkste project in die onderzoeksagenda over naming and shaming van ondernemingen in mondiale markten. 'Reputatie' wordt naast formele controle vaak genoemd als een van de belangrijkste informele controlemechanismen voor ondernemingen. De dreiging van reputatieschade zou schadelijk gedrag van ondernemingen voorkomen, en de afschrikwekkende werking van juridische sancties kunnen versterken, zeker in een tijdperk van wereldwijde verbondenheid, waarin sociale media binnen korte tijd een verwoestende uitwerking kunnen hebben. Er heerst daarom groot optimisme met betrekking tot de effectiviteit van naming and shaming, als middel om sociale normen te articuleren en te handhaven in de global village.

Hier dringt zich allereerst een instrumentele beleidsvraag op. Talloze inspecties en markttoezichthouders stellen zich de vraag of zij aan naming and shaming moeten doen, en hoe. Maar in lijn met het eerdere commentaar kunnen ook minder instrumentele vragen worden gesteld. Vanuit organisatiesociologisch perspectief is er bijvoorbeeld de vraag of en hoe 'schaamte' kan worden gevoeld binnen organisaties, en of en hoe dit leidt tot gedragsverandering in de onderneming of de sector. Daarnaast blijkt uit veel nieuw onderzoek in de institutionele organisatiesociologie dat reputatieschade soms juist ondernemingen treft die een positief beleid voeren en schadelijker ondernemingen ongemoeid laat (Comyns \& Fran- 
klin-Johnson, 2018); dat ondernemingen geleid door minderheden negatiever worden bejegend en meer reputatieschade lijden (Park \& Westphal, 2013); en dat sommige overtredingen juist bijdragen aan een reputatie van onverschrokkenheid die nieuwe klanten met risicobereidheid kan aantrekken (Roulet, 2018). Dit brengt niet alleen de vraag naar effectiviteit, maar ook naar rechtvaardigheid met zich mee.

Vanuit juridisch perspectief is de vraag aan de orde naar proportionaliteit van reputatiesancties. Sommige juristen stellen dat reputatiesancties zo groot zijn dat ze juridische sancties overbodig maken (Iacobucci, 2014). Tegelijkertijd waarschuwen veel juristen voor de buitenproportionele effecten van reputatiesancties. De kracht van het instrument is tegelijkertijd zijn zwakte. In eerder onderzoek constateerde ik dat openbaarmaking van sancties door publieke toezichthouders voor grote financiële instellingen vaak uitpakt als naming without shaming maar kleinere organisaties soms onevenredig zwaar kan treffen (Van Erp, 2011). Ik concludeerde ook dat mediaberichtgeving over sancties voor organisatiecriminaliteit vaak het frame hanteert van de machtsstrijd tussen toezichthouder en overtredende onderneming, waarbij het eerder gaat om de vraag wie de dienst uitmaakt, dan om morele oordeelsvorming over de schade van fraude (Van Erp, 2013). Nu in het huidige discours ondernemingen veel kritischer worden beoordeeld, ben ik benieuwd in hoeverre deze conclusies uit onderzoek in de periode voor de financiële crisis standhouden.

De groei van internet en de opkomst van sociale media hebben een veel grotere pluriformiteit van 'media' gecreëerd, waarbij meer ruimte is voor slachtoffers (al dan niet vertegenwoordigd door mondiale NGO's) om zichtbaar te worden, en meer mogelijkheden zijn ontstaan om schadelijk gedrag van ondernemingen te onthullen via anoniem lekken. Daardoor zijn reputaties van ondernemingen kwetsbaarder, maar tegelijkertijd biedt technologie hun nieuwe mogelijkheden om beeldvorming te beïnvloeden en kan de verspreiding van negatieve informatie beperkt blijven door 'filter bubbles'. Al met al is reputatie een ambigu begrip en is reputatieschade buitengewoon onvoorspelbaar.

De impact van naming and shaming blijft mij daarom bezighouden. Op de vraag welke plaats reputatie inneemt in het geheel aan formele en informele regulerings- en governance mechanismen in mondiale markten, en de vraag of en hoe toezichthouders strategisch om kunnen gaan met reputatieschade die hun optreden bij organisaties veroorzaakt, hoop ik de komende jaren een antwoord te vinden.

\section{Literatuur}

Almond, P., \& Erp, J. van. (2019). Regulation and governance versus criminology: Disciplinary divides, intersections, and opportunities. Regulation \& Governance, online first.

Barak, G. (2015). The Routledge internationalhHandbook of the crimes of the powerful. London: Routledge.

Boutellier, H. (2005). De veiligheidsutopie: hedendaags onbehagen en verlangen rond misdaad en straf. Den Haag: Boom Juridische uitgevers. 
Braithwaite, J., Coglianese, C., \& Levi-Faur, D. (2007). Can regulation and governance make a difference?, Regulation \& Governance, 1(1), 1-7.

Claassen, R., \& Erp, J. van. (2019). Markten en Ondernemingen in de Open Samenleving. Den Haag: Boom bestuurskunde, te verschijnen.

Coen, D., \& Pegram, T. (2018). Towards a third generation of global governance scholarship. Global Policy, 9(1), 107-113.

Comyns, B., \& Franklin-Johnson, E. (2018). Corporate reputation and collective crises: a theoretical development using the case of Rana Plaza. Journal of Business Ethics, 150, 159-183.

Erp, J. van. (2011). Naming without shaming: the publication of sanctions in the Dutch financial market. Regulation \& Governance, 5, 287-308.

Erp, J. van. (2013). Messy business, media representations of administrative sanctions for corporate offenders. Law \& Policy, 35, 109-139.

Erp, J. van. (2016). Toezicht in de Open Samenleving. Maatschappelijke controle op multinationale ondernemingen (oratie). Den Haag: Boom bestuurskunde.

Erp, J. van, \& Steen, M. van der. (2018). Wetenschapsagenda Toezicht. Inspectieraad/USBO Advies. https://www.rijksinspecties.nl/publicaties/publicaties/2018/04/24/ wetenschapsagenda-toezicht

Fenger, M. (2016). Van wie is de Verzorgingsstaat? Over het eigenaarschap van publieke instituties (oratie). NSOB/Erasmus Universiteit.

Iacobucci, E.M. (2014). On the interaction between legal and reputational sanctions. The Journal of Legal Studies, 43, 189-207.

Jordana, J., Fernández-i-Marín, X., \& Bianculli, A. (2018). Agency Proliferation and the globalization of the regulatory state: introducing a data set on the institutional features of regulatory agencies. Regulation \& Governance, 12(4), 524-540.

Jordanoska, A., \& Lord, N. (2019). Scripting the mechanics of the benchmark manipulation corporate scandals: the 'guardian' paradox. European Journal of Criminology, forthcoming.

Levi-Faur, D. (2012). From 'Big government' to 'Big governance’? In D. Levi-Faur (Ed.), Oxford handbook of governance (pp. 3-19). Oxford University Press.

Levi-Faur, D. (2013). The odyssey of the regulatory state: From a 'thin' monomorphic concept to a 'thick' and polymorphic concept. Law \& Policy, 35(1-2), 29-50.

Lodge, M. (2016). Regulation crisis in scholarship. CARR discussion paper no. 84 (London: London School of Economics).

Majone, G. (1994). The rise of the regulatory state in Europe. West European Politics, 14(3), 77-101.

Mascini, P. (2013). The enforcement pyramids' influence. Regulation \& Governance, 7, 48-60.

Meerts, C. (2018). The organisation as the cure for its own ailments: corporate investigators in the Netherlands. Administrative Sciences, 8(3), 1-15.

Mills, R.W., \& Koliba, C.J. (2015). The challenge of accountability in complex regulatory networks: the case of the Deepwater Horizon oil spill. Regulation \& Governance, 9, 77-91.

Nelken, D. (2012). White collar and corporate crime. In M. Maguire, R. Morgan \& R. Reiner (Eds.), The Oxford Handbook of Criminology (pp. 623-659). Oxford: Oxford University Press.

Pearce, F. (1976). Crimes of the powerful: marxism, crime and deviance. London: Pluto Press.

Roulet, T.J. (2018). Sins for some, virtues for others: media coverage of investment banks' misconduct and adherence to professional norms during the financial crisis. Human Relations, online first . 
Park S., \& Westphal, J. (2013). Social discrimination in the corporate elite: how status affects the propensity for minority CEOs to receive blame for low firm performance. Administrative Science Quarterly, 58(4), 542-586.

Roberts, A. (2010). The logic of discipline: global capitalism and the architecture of government. Oxford University Press.

Rooij, B. van, \& Fine, A. (2018). Toxic corporate culture: assessing organizational processes of deviancy. Administrative Sciences, 8(3), 1-38.

Ruggie, J.G. (2018). Multinationals as global institutions: power, authority and relative autonomy. Regulation \& Governance, 12, 317-333.

Schuilenburg, M. (2012). Orde in veiligheid, Een dynamisch perspectief. Den Haag: Boom bestuurskunde.

Wal, Z. van der. (2017). De 21e-eeuwse overheidsmanager, een reis door tijd, plaats en context. Oratie Universiteit Leiden, Caop.

Wetenschappelijke Raad voor het Regeringsbeleid (WRR). (2013). Toezien op publieke belangen. Naar een verruimd perspectief op rijkstoezicht. Amsterdam: Amsterdam University Press.

Whyte, D. (2014). Regimes of permission and state-corporate crime. State Crime Journal, 3(2), 237-246.

Wingerde, K. van, Mascini, P., \& Barth, J.W. (2018). De praktijk van toezicht in een neoliberaal tijdperk. Een case study van de taakuitvoering door ISZW-inspecteurs bij de handhaving van de arbeidsomstandigheden. Reeks Handhaving en Gedrag. Den Haag: Boom criminologie. 